\title{
Imagem corporal: a descoberta de si mesmo
}

\author{
Body image: discovering one's self
}

\section{Daniela Dias Barros}

Professora de Educação Física da Universidade Paranaense (Unipar)

Rua Fortaleza 389 ap. 1201,

Alto da Glória

74815-120 Goiânia - GO Brasil

ddbarros@yahoo.com.br
BARROS, D. D.: Imagem corporal: a descoberta de si mesmo. História, Ciências, Saúde - Manguinhos, v. 12, n. 2: p. 547-54, maio-ago. 2005.

Este trabalho estuda a contribuição da imagem corporal a partir de seus múltiplos componentes e suas implicações tanto fisiológicas como sociais. O trabalho fornece um breve histórico do surgimento dos estudos de imagem corporal; algumas considerações sobre a fisiologia e os aspectos sociais, e quais as suas influências na imagem de corpo. Optou-se por fazer uma pesquisa bibliográfica para construir um conceito de imagem corporal que fosse consistente, baseado em grandes estudiosos como Paul Schilder, Thomas F. Cash e Thomas Pruzinsky. Mostramos que a todo instante construímos nossas próprias imagens corpóreas, uma vez que cada imagem construída influencia quem está ao nosso redor e vice-versa.

PALAVRAS-CHAVE: imagem corporal; corpo; corporeidade.

BARROS, D. D.: Body image: discovering one's self.

História, Ciências, Saúde - Manguinhos,

v. 12 , n. $2,++$ p. 547-54, May-Aug. 2005

The article examines body image from the perspective of its various components and its physiological and social implications. It provides a brief historical background on the beginnings of body image studies, as well as some considerations about physiology and social aspects and how they influence body image. Lastly, bibliographic research based on such great scholars as Paul Schilder, Thomas F. Cash, and Thomas Pruzinsky is used to underpin the construction of a consistent concept of body image, showing how at each and every moment we create our own body image, since each image that we create influences whoever is around us, and vice versa.

KEYWORDS: body image; body; embodiment. 


\section{Aspectos históricos da imagem corporal}

história da imagem corporal iniciou-se no século XVI, na Fran-
exa, com o médico e cirurgião Ambroise Paré, que percebeu a
existência do membro fantasma, caracterizando-o como a alucina-
ção de que um membro ausente estaria presente. Três séculos depois,
Weir Mitchell, da Filadélfia (EUA), demonstrou que a imagem cor-
poral (sem se referir ao termo 'imagem corporal') pode ser mudada
sob tratamento ou em condições experimentais (Gorman, 1965).

A escola francesa também deixou sua contribuição com os estudos de Bonnier, o qual, em 1905, descreveu um distúrbio em toda imagem corporal como 'esquematia' (distorção do tamanho das áreas corpóreas).

Mas foi na escola britânica que os estudos sobre imagem corporal aprofundaram-se, tanto nos aspectos neurológicos quanto nosfisiológicos e psicológicos. O neurologista Henry Head, do London Hospital, foi o primeiro a usar o termo 'esquema corporal' e também o primeiro a construir uma teoria na qual "cada indivíduo constrói um modelo ou figura de si mesmo que constitui um padrão contra os julgamentos da postura e dos movimentos corporais" (Fisher, 1990, p. 5).

Head demonstrou que qualquer alteração postural pode mudar o que ele chamou de esquema corporal (schemata): “Qualquer coisa que participe do movimento consciente de nossos corpos é somada ao nosso modelo corporal e torna-se parte deste schemata" (Gorman, 1965, p. 48).

Mas a maior contribuição nesta área foi dada por Paul Schilder, pois desenvolveu sua experiência tanto na neurologia quanto na psiquiatria, assim como na psicologia. Schilder considera a imagem corporal um fenômeno multifacetado. Em suas investigações, "ele analisou a imagem corporal não apenas no contexto do orgânico, mas também na psicanálise e na sociologia" (Fisher, 1990, p. 8). Em sua definição de imagem corporal, diz que "a imagem corporal não é só uma construção cognitiva, mas também uma reflexão dos desejos, atitudes emocionais e interação com os outros" (ibidem). Mas uma de suas mais importantes reflexões consistiu na introdução da idéia de que a imagem do corpo não possui apenas fatores patológicos: os eventos diários também contribuem para sua construção.

Nesse ponto, a utilização do termo 'imagem corporal' começa a surgir e com ela algumas considerações a respeito de qual seria o termo correto: esquema ou imagem corporal. Houve uma predominância do termo 'esquema corporal' na neurologia e de 'imagem corporal' nos meios da psicologia. Por isso a confusão em saber qual dos dois é o mais apropriado. Alguns autores acreditam que há realmente uma diferença entre ambos. 
Rodrigues (1987, p. 18) distingue-os alegando que "esquema corporal é conotado como uma estrutura neuromotora que permite ao indivíduo estar consciente do seu próprio corpo anatômico, ajustando-o às solicitações de situações novas, e desenvolvendo ações de forma adequada".

Olivier (1995) também concorda com essa distinção e afirma que a imagem do corpo constrói-se sobre o esquema corporal. Le Boulch (1992, p. 18) afirma que "a ambigüidade introduzida por esta dupla terminologia cria a impressão de que existiria, por um lado, um corpo neurológico, e, por outro lado, um corpo espiritual e teria que se fazer esforço para unir os dois corpos".

Dessa maneira, sendo o ser humano um corpo uno, parece-nos paradoxal que haja uma distinção como essa. O esquema corporal interpõe-se na imagem corporal e vice-versa, formando um único conceito, não importando qual deles usar.

\section{Considerações fisiológicas e sociais da imagem corporal}

Existem reações fisiológicas ocorrendo o tempo todo em nosso corpo. No entanto, quando essas reações orgânicas estão prejudicadas, podem afetar a imagem que uma pessoa tem de si mesma. Relatos de Head citados por Schilder (1999) constataram que, quando a imagem visual é preservada e a sensibilidade está prejudicada, ainda assim é possível que o indivíduo diga exatamente onde foi tocado. Esse é um caso de hipotonia, isto é, uma lesão cortical que leva a um distúrbio da sensibilidade e, conseqüentemente, à mudança da imagem corporal. Isso pode provar o quanto a visão influencia na percepção de si mesmo, pois a imagem visual do corpo permanece mesmo que haja dificuldades na sensibilidade.

Sabe-se também que o toque pode provocar uma imagem mental do local tocado, e tais imagens ajudam consideravelmente em sua localização. Embora isso aconteça, "as imagens visuais que se encontram em nossa consciência são apenas uma pequena parte daquilo que está realmente ocorrendo na esfera psíquica" (Schilder, 1999, p. 18).

Shontz (1990) afirma que a organização da imagem corporal não é puramente neurológica nem mental. Acredita-se também que as emoções tenham um papel importante no desenvolvimento da imagem corporal.

Na verdade, há uma interação entre os lados fisiológico, neural e emocional, além do fator social. Um desses processos analisados separadamente tornaria a análise falha e incompleta. Mudanças em um deles podem ocasionar conseqüências na experiência do corpo.

Um caso típico é o que chamamos de 'membro fantasma'. Ambroise Paré (século XVI) foi quem o descreveu pela primeira vez 
e fez o relato de que essa expressão é usada se ocorrer uma amputação de alguma parte do corpo.

As sensações provenientes do membro fantasma são principalmente táteis e cinestésicas. Sua posição normalmente é rígida, ou seja, fica a imagem de quando o indivíduo perdeu o membro. É como se houvesse a necessidade de registrar os últimos instantes em que o membro estava presente. A maioria das pessoas sente dor, tem vontade de coçar, acha que pode movimentá-lo e, durante alguns segundos, esquece que não tem o membro (Schilder, 1999).

Essas são situações peculiares que intrigam muitos pesquisadores e que, com certeza, afetam toda a imagem corporal de uma pessoa. Schilder ainda afirma que possuímos a capacidade de mudar nossa imagem continuamente. E essa multiplicidade de imagens só pode ser conseguida pelas forças emocionais. É por meio delas que entendemos a variedade de fantasmas que uma pessoa é capaz de criar em seu próprio corpo.

Unindo os aspectos fisiológicos com as forças emocionais, a imagem vai condensando a vivência que o homem tem de si mesmo e do mundo. Resgata o passado, funde-se com o presente e transcende para o futuro, ultrapassando as fronteiras do imaginário humano. Faz-se ser atuante perante as correlações estabelecidas por ele mesmo, constituindo-se presente em imagens corpóreas (Barros, 2001).

Assim sendo, as imagens corporais ligam-se por meio de uma proximidade espacial que favorece o contato entre corpos e suas experiências. Sua construção torna-se mais fácil e rica e as trocas de vivências entre duas ou mais pessoas são maiores. Isso se deve à incorporação de diversas partes das imagens corporais dos outros e à doação de nossas próprias imagens a eles. Aliado a isso, o fator emocional aparece como peça-chave neste processo, pois podemos estabelecer uma relação íntima com determinada pessoa. Trocamos nossas imagens corporais. É uma experiência de sentidos. Como nos diz Schilder (1999, p. 250), "primeiro, temos uma impressão sensorial do corpo do outro. Esta impressão adquire seu significado real através de nosso interesse emocional pelas diversas partes do corpo".

É importante ressaltar também que, quando percebemos nosso corpo ou partes dele, projetamos essas imagens para outros corpos e passamos a ter curiosidade sobre outras partes que, até então, eram-nos obscuras. Na verdade, fica difícil dizer qual corpo percebemos primeiro: o nosso ou o do outro. Portanto, “a imagem é um fenômeno social ... pois há um intercâmbio contínuo entre nossa própria imagem e a imagem corporal dos outros" (Schilder, 1999, p. 240-51). 


\section{A descoberta de si mesmo}

Nosso corpo é, antes de tudo, nosso primeiro e maior mistério. Para estarmos realmente presentes no mundo, é preciso reconhecer que somos um corpo em sua imensidão de complexos processos que nos fazem ricos em sua consciência e inconsciência desconcertantes e pragmáticas e em suas atitudes, que são sempre corporais.

Construímos e destruímos discursos corporais que resultam em um conhecimento de nossa vida. O corpo, então, é o lugar onde há a quebra da simetria, onde tudo pode acontecer e acontece (Barros, 2001).

Também construímos e destruímos nossa imagem corporal. É uma sucessão de tentativas para buscar uma imagem e corpos ideais. E esse mundo de imagens corporais que permeia nossas vidas está pleno de emoções. Jung (1997) nos diz que as imagens precisam estar cheias de emoções para termos numinosidade, ou seja, para nos identificarmos com tais emoções e assumirmos as várias conseqüências que elas acarretam.

É importante ressaltar, ainda, que os fatores já citados que fazem parte da imagem corporal só a tornam completa se todos estiverem unidos. Um fator por si só seria incompleto e insuficiente. Schilder (1999, p. 311) nos fala que "nossa imagem corporal só adquire suas possibilidades e existência porque nosso corpo não é isolado. Um corpo é, necessariamente, um corpo entre corpos. Precisamos ter outros à nossa volta".

Mas, então, qual seria o conceito de imagem corporal mais próximo da realidade? Muitos autores elaboraram suas visões com base em experiências empíricas. Cash e Pruzinsky (1990) elaboraram sete afirmações que melhor abrangem o conceito de imagem corporal. São elas:

1. Imagem corporal refere-se às percepções, aos pensamentos e aos sentimentos sobre o corpo e suas experiências. Ela é uma experiência subjetiva.

2. Imagens corporais são multifacetadas. Suas mudanças podem ocorrer em muitas dimensões.

3. As experiências da imagem corporal são permeadas por sentimentos sobre nós mesmos. O modo como percebemos e vivenciamos nossos corpos relata como percebemos a nós mesmos.

4. Imagens corporais são determinadas socialmente. Essas influências sociais prolongam-se por toda a vida.

5. Imagens corporais não são fixas ou estáticas. Aspectos de nossa experiência corporal são constantemente modificados.

6. As imagens corporais influenciam o processamento de informações, sugestionando-nos a ver o que esperamos ver. A ma- 
neira como sentimos e pensamos o nosso corpo influencia o modo como percebemos o mundo.

7. As imagens corporais influenciam o comportamento, particularmente as relações interpessoais.

Como se pode notar, trata-se de um conceito amplo, que envolve vários aspectos pertinentes ao tema. Por isso, se encaixa melhor em uma definição satisfatória, já que imagem corporal abrange os processos fisiológicos, psicológicos e sociais, num intercâmbio contínuo entre eles. É uma experiência que vivemos a cada instante e nunca é verdadeiramente unilateral. Ela busca a diversidade de seus aspectos e emaranha-se às imagens alheias. Transforma as relações externas com o mundo e é transformada por elas. Reflete sua mais profunda intimidade, expondo, assim, sua face. Apresenta-se como a parte mais consistente de nosso interior mostrando-se ao mundo. Simboliza todo o nosso ser, apesar de nunca ser completa e esconder mistérios numa dimensão paradoxal.

Sua construção envolve a possibilidade de interferência sobre a própria auto-imagem de cada um, uma vez que ela - a imagem corporal - não é fixa. Olivier (1995, p. 48) cita que “o corpo e sua utilização passam por um processo de aprendizagem construtor de hábitos". Aqui, encerra-se o ponto crucial da modificação constante de nossa auto-imagem. Ela, então, é definida a partir das interferências sociais que sofremos e dos hábitos que criamos, moldando nosso aspecto de existir como seres corporais.

As informações que obtemos sobre os diversos aspectos que formam o mundo - por exemplo, as novas tecnologias, a mídia e seu ávido poder consumista - são apreendidas por nós como uma parte de nosso corpo unindo-se com nossa imagem corporal, transformando-nos em camaleões que se adaptam àquilo que as circunstâncias exigem. Nossa percepção de mundo passa a ser lograda a partir de tais influências, e nos sujeitamos a ver essas transformações com os limites impostos por nós mesmos.

Nosso comportamento é, portanto, comandado por esses limites, que são as percepções individuais que criamos e sobre as quais exercemos certo controle, e que também afetam as relações interpessoais, na medida em que acolhemos uma imagem corporal tendo em vista a sua mobilidade e transformação constante, estabelecendo uma interface de relacionamentos que se moldam pela nossa própria imagem e a do outro, mesclando-se numa troca de informações subjetivas que irá criar novas imagens de corpo e de mundo.

Schilder (1999, p. 125) afirma que "a imagem corporal, em seu resultado final, é uma unidade. Mas essa unidade não é rígida, e sim passível de transformações". A unidade a que se refere são todas as possibilidades de unir as diversas relações e experiências que 
desenvolvemos ao longo de nossa vida, buscando sentido através de uma totalidade corporal e imagética de nós mesmos em constante transformação.

$\mathrm{O}$ ato de construir discursos e imagens corporais de nós mesmos resulta em desvelar a descoberta de imagens que nos permeiam de forma a nos satisfazer no maior número de correlações sociais possíveis. Faz-nos perceber que imagem corporal é a nossa totalidade como seres humanos. E a transcendência em olhar interna e externamente e perceber que somos fruto de nossas atitudes (físicas, mentais e emocionais) e, conseqüentemente, as imagens do corpo formam-se a partir delas. E sendo totalidade podemos, enfim, abranger os conhecimentos de estudiosos e nosso próprio modo de compreender sua significação, aumentando o círculo.

É aliar um conceito à nossa consciência de que somos corpos em lugares distintos residindo em nossa própria manifestação material e física, pois "a consciência amplia o impacto desses sentimentos nas mentes dos personagens desta cena" (Damásio, 2000, p. 20), que nada mais é do que a vida em sua concretude e nuanças.

O corpo e a sua imagem são elementos simbólicos e materiais que ocupam um momento no espaço e no tempo através do conhecimento, que é sempre renovável e translúcido. Transforma-se na razão direta de sua fugacidade em saber e exigir "ser entendido a partir de um lugar: um lugar que o reconheça no pormenor, mas que o identifique no todo" (Silva, 1999, p. 26).

O corpo, portanto, transforma-se em um palco de imagens corporais construídas. E as descobertas que temos de nós mesmos vão se revelando a partir do instante em que nos reconhecemos como um 'ser' que reage às diversas inter-relações estabelecidas pelos mesmos corpos que tentam realizar a busca pela compreensão da existência de imagens - a busca por sua própria existência.

\section{REFERÊNCIAS BIBLIOGRÁFICAS}

Barros, Daniela Dias 2001

Cash, Thomas. F.; Pruzinsky, Thomas 1990

Damásio, Antonio 2000

Fisher, Seymour 1990
Estudo da imagem corporal da mulher: corpo (ir)real x corpo ideal.

Dissertação de mestrado, Campinas, Faculdade de Educação Física, Unicamp.

Body images: development, deviance and change.

New York: The Guilford Press.

O mistério da consciência: do corpo e das emoções ao conhecimento de si. São Paulo: Companhia das Letras.

The evolution of psychological concepts about the body.

In: Cash, Thomas. F.; Pruzinsky, Thomas (ed.) Body images: development, deviance and change. New York: The Guilford Press, p. 4-18. 
Gorman, Warren 1965

Jung, Carl Gustav 1997

Le Boulch, Jean 1992

Olivier, Giovanina

Gomes de Freitas 1995

Rodrigues, David

Antonio 1987

Schilder, Paul 1999

Shontz, Franklin C. 1990

Silva, Paulo Cunha e 1999
Body image and the image of the brain.

St. Louis (USA): Warren H. Green.

O homem e seus símbolos.

15. ed. Rio de Janeiro: Nova Fronteira.

O desenvolvimento psicomotor: do nascimento aos seis anos. Porto Alegre: Artes médicas.

Um olhar sobre o esquema corporal, a imagem corporal, a consciência corporal e a corporeidade. Dissertação de Mestrado, Campinas, Faculdade de Educação Física, Unicamp.

Corpo, espaço e movimento: estudo da relação entre a representação espacial do corpo e o controle da manipulação e da locomoção em crianças em paralisia cerebral. Tese de Doutoramento, Lisboa, Universidade Técnica de Lisboa.

A imagem do corpo: as energias construtivas da psique.

3. ed. São Paulo: Martins Fontes.

Body image and Physical disability. In: Cash, Thomas F.; Pruzinsky, Thomas (ed.) Body images: development, deviance and change. New York: The Guilford Press, p. 149-68.

O lugar do corpo: elementos para uma cartografia fractal. Lisboa: Instituto Piaget.

Recebido para publicação em agosto de 2004. Aprovado para publicação em dezembro de 2004. 